\title{
AN EXAMINATION OF STUDENT LEARNING OF SCIENCE CONCEPTS USING INTERACTIVE INSTRUCTIONAL MULTIMEDIA TECHNOLOGY
}

\author{
Maria Georgiou \\ School of Education, Northcentral University, 85255 Arizona, 92106 San Diego, California, United States of America \\ Cyprus Ministry of Education and Culture, 1434 Nicosia, Cyprus
}

\begin{abstract}
This study examined if there were any significant differences in students' achievement scores in science for three units that were taught using traditional methods of instruction and a unit that was taught using a multimedia-based instruction. A one-way repeated measures ANOVA was carried out to assess if the differences between the test means were significantly different. Findings showed that students' scores for the four units were significantly different, $\mathrm{F}(3,219)=22.702, \mathrm{p}<0.0005$. Students scored higher on the posttest after the use of interactive multimedia technology in instruction. The results of the current study indicate the need to change educational anticipations, as teaching methods become more active, student-centered and constructivist. Multimedia has attributes that can help students improve their learning and motivation while being engaged in active and constructivist learning environments. The use of instructional interactive multimedia provides more than one learning modality that can be more effective in meeting students' learning needs.
\end{abstract}

\section{KEYWORDS}

Constructivist Learning Environment, Multimedia

\section{INTRODUCTION}

Science teaching has changed in the last years to include a more constructivist approach to teaching that is more student-centered and allows students to explore ideas and experience real life situations that promote problem-solving and higher order thinking skills (Birgan, 2010; Dalal, 2014; Hunter \& Krantz, 2010). This student-centered approach promotes also creativity, critical thinking and communication skills that are lacking in today's science students (So \& Kong, 2007; Ulusoy, 2011). Researchers have found that teaching science with a constructivist approach provides active, student-centered learning environments that can improve student interaction and allow knowledge construction (Adegoke, 2011, Butts, 2008).

Research has shown that students receiving computer-based instruction learn $40 \%$ faster than students receiving traditional-based instruction (Dalal, 2014; Stokes, 2011). Traditional-based instruction refers to an instructional communication where the instructor has the overall control in the classroom and sends the educational material to the students who mostly learn at the same pace (Delgado, 2007). Traditional methods of instruction mainly focus on memorization of educational information by the students who passively receive information (Malik, 2010). This method of instruction includes lectures only and lacks of the use of technology tools (Yamauchi, 2008).

Multimedia tools that combine text, audio, video, animation and images have been found to be progressive instructional tools when used in the learning environment (Adegoke, 2011; Singleton, 2009). For instance, multimedia technology can help difficult concepts in science to be visually presented (Birgan, 2010). The use of multimedia in science can help students increase their emotional involvement because multimedia connects students with inaccessible places (Ulusoy, 2011). The use of multimedia technology in science instruction can improve student learning and allow students to be actively engaged in the learning process (Malik, 2010; Morano, 2014). Multimedia can appeal to more than one sense and increase students' success and motivation (Weiss, Kramarski, \& Talis, 2006). Motivation is directly related to metacognition and when students feel excited about learning with multimedia then their metacognitive thinking process may 
be stimulated (Cottrell, 2014; Dalal, 2014). Multimedia can motivate students because it can stimulate curiosity and make students wonder about the world around them (Mazzotti, 2010; Ulusoy, 2011).

Constructivist learning environments include active learning and help promote critical thinking and problem-solving skills that can be enhanced through the use of multimedia (Butts, 2008; Du, 2013). A multimedia-based instruction that applies the constructivist principles is more authentic and promotes collaboration among the students (Birgan, 2010). The use of multimedia can be a factor that can affect student learning and achievement because multimedia learning supports the idea that learning is not a process of knowledge absorption but rather a process of knowledge construction that promotes critical thinking (Dalal, 2014; Singleton, 2009). A multimedia-based learning environment in which constructivist principles are applied can motivate students to want to learn because the constructivist theory is based on the idea of discovery learning that supports that students are motivated towards the lesson (Johnson, 2009; Rhodes, 2013). With multimedia instruction students learn faster because the educational material is processed through various presentations that can improve student understanding (Dalal, 2014; Rhodes, 2013; Zheng, Yangt, Garcia, \& McCadden, 2008). In contrast to traditional methods of instruction, a multimedia-based instruction allows students to create their own learning sequence and this helps them develop and promote important skills that are necessary in order to become independent learners (Adegoke, 2011; Cottrell, 2014; Kingsley \& Boone, 2008).

Students' achievement in science is low because of incompetent methods of instruction and passive learning (Adegoke, 2011; Malik, 2010). The purpose of this quantitative study was to examine if there were any significant differences in students' achievement in science for three units that were taught using traditional methods of instruction and a unit that was taught using interactive multimedia technology in instruction. The study focused on the following research question: Is there a significant difference between the four units and students' scores? The hypotheses were as follows: H10. There is no significant difference between the four units and students' scores. H1a. There is a significant difference between the four units and students' scores.

\section{METHODOLOGY}

The study used a quasi-experimental with a one group pre-posttest research design. A total of 320 third grade students constituted the population group because of low achievement scores (Papanastasiou \& Zembylas, 2004). The sample for this study was selected using a convenience sampling method and included a total of 74 students. A Power analysis was conducted that showed that a total of 74 students were sufficient for a sample at the $95 \%$ confidence level, with a confidence interval of 5\%. Participants attended five 80 minute science lessons in which interactive multimedia technology was used. All of the instructional material was entered into the multimedia program HyperStudio that was used in the multimedia-based instruction. This multimedia software is a creativity tool that can be used for project-based learning and creating stacks of cards that may include text, images, animations, sounds, and video (Garthwait, 2004).

Data were collected from pretest and posttest scores as well as from archival data that included students' tests scores for three past science units that were taught using traditional methods of instruction. Statistical analyses were conducted using SPSS, version 20. Descriptive statistics such as means and standard deviations were used to describe the general tendencies in the data (Trochim \& Donnelly, 2008). Also, measures of central tendency, the median and mode, were used to describe the average scores of the participants. One-way repeated measures ANOVA was conducted in order to compare students' scores on tests for the four units and to determine whether the differences, between the score means, were significantly different. Assumptions of the one-way repeated measures ANOVA were also tested.

\section{RESULTS AND DISCUSSION}

For the results to be valid, the normality assumption for the one-way repeated measures ANOVA should hold. Science achievement (dependent variable) should be approximately normally distributed for the four science units (independent variable). A Shapiro-Wilk's test and a visual review of the histograms, normal Q-Q plots and box plots showed that science achievement was approximately normally distributed for the 
four science units, with a skewness of -0.116 and a kurtosis of -0.942 for unit 1 ; a skewness of -0.079 and a kurtosis of -0.738 for unit 2 ; a skewness of -0.157 and a kurtosis of -0.781 for unit 3 ; and a skewness of -0.589 and a kurtosis of 0.218 for unit 4 (posttest). All z-values of skewness and kurtosis for the four units were within $+/-1.96$. We can assume that the data are approximately normally distributed in terms of skewness and kurtosis.

The null hypothesis for the Shapiro-Wilk's test is that the data are normally distributed. The null hypothesis is rejected if the p-value is below 0.05. As shown in Table 1, all p-values are above $0.05(0.214$, $0.214,0.301,0.096)$, so the alternative hypothesis is rejected. In terms of the Shapiro-Wilk test, we can assume that the data are approximately normally distributed. Additionally, the histograms, normal Q-Q plots and box plots were examined for the four units. All histograms had the approximate shape of a normal curve. The data are approximately normally distributed and approximately symmetrical.

Table 1. Tests of Normality

\begin{tabular}{|c|c|c|c|c|c|c|}
\hline \multirow{2}{*}{} & \multicolumn{2}{|l|}{ Kolmogorov-Smirnov $^{\mathrm{a}}$} & \multicolumn{2}{l|}{ Shapiro-Wilk } & Sig. \\
\cline { 2 - 7 } & Statistic & $\mathrm{df}$ & Sig. & Statistic & $\mathrm{df}$ & .214 \\
\hline $\mathrm{u} 1$ & .109 & 74 & .083 & .952 & 74 & .214 \\
\hline $\mathrm{u} 2$ & .101 & 74 & .201 & .952 & 74 & .301 \\
\hline $\mathrm{u} 3$ & .115 & 74 & .052 & .958 & 74 & .096 \\
\hline $\mathrm{u} 4$ & .121 & 74 & .041 & .967 & 74 & \\
\hline
\end{tabular}

Mauchly's Test of Sphericity was carried out in order to test the sphericity assumption. As shown in Table 2, the assumption of sphericity has been met, $x^{2}(5)=10.478, p=.063$. If the data are perfectly spherical in the population, there is a $6,3 \%$ chance of finding the deviation from sphericity that is observed in this sample. It is therefore assumed that the sphericity assumption has been met. The data seem spherical.

Table 2. Mauchly's Test of Sphericity

\begin{tabular}{|l|l|l|l|l|l|l|l|}
\hline Measure: MEASURE_1 & Mauchly's W & $\begin{array}{l}\text { Approx. } \\
\text { Chi-Square }\end{array}$ & df & Sig. & \multicolumn{2}{|l|}{ Epsilon } & \\
\cline { 3 - 7 } & Within Subjects Effect & Greenhouse- & $\begin{array}{l}\text { Huynh- } \\
\text { Feldt }\end{array}$ & $\begin{array}{l}\text { Lower- } \\
\text { bound }\end{array}$ \\
\hline unit & .812 & 10.478 & 5 & .063 & .867 & .916 & .333 \\
\hline
\end{tabular}

The means and standard deviations are shown in Table 3. On average, the highest scores were gained on the posttest for science unit $4(\mathrm{M}=88.46)$.

Table 3. Descriptive Statistics

\begin{tabular}{|l|l|l|l|}
\hline & Mean & Std. Deviation & N \\
\hline u1 & 86.4930 & 5.74581 & 74 \\
\hline $\mathrm{u} 2$ & 87.1375 & 5.23560 & 74 \\
\hline $\mathrm{u} 3$ & 88.1754 & 5.32678 & 74 \\
\hline $\mathrm{u} 4$ & 88.4657 & 3.56718 & 74 \\
\hline
\end{tabular}


As shown in Table 4, there was a significant effect for the science units, Wilks's Lambda $=.52$, $\mathrm{F}(3,71)=12.659, \mathrm{p}<.0005$, multivariate partial squared $=.438$ (large effect size). The results indicate that students' scores increased significantly over time and over the units. The $p<.05$ and therefore there is a statistically significant effect for the units. There was a change in students' scores throughout the units. The significant p-values show an effect of the independent variable on the dependent variable as revealed by the repeated measures. All the multivariate tests show a significant interaction between the units and students' scores, indicating that the science units had a significant effect on students' scores over time.

Table 4. Multivariate Tests

\begin{tabular}{|l|l|l|l|l|l|l|}
\hline \multicolumn{2}{|l|}{ Effect } & Value & F & Hypothesis df & Error df & Sig. \\
\hline \multirow{3}{*}{ unit } & Pillai's Trace & .427 & $12.659^{\mathrm{b}}$ & 3.000 & 71.000 & .000 \\
\cline { 2 - 8 } & Wilks' Lambda & .526 & $12.659^{\mathrm{b}}$ & 3.000 & 71.000 & .000 \\
\cline { 2 - 8 } & Hotelling's Trace & .812 & $12.659^{\mathrm{b}}$ & 3.000 & 71.000 & .000 \\
\cline { 2 - 7 } & Roy's Largest Root & .812 & $12.659^{\mathrm{b}}$ & 3.000 & 71.000 & .000 \\
\hline
\end{tabular}

The results of the Tests of Within-Subjects Effects are presented in Table 5. There was a significant effect of science unit on students' scores, $F(3,219)=22.702, p=.000$. Specifically, there is a significant difference between the four unit tests in terms of the average score gained. The p-value is .000 , which means that if the means are perfectly equal in the population, there is a $0 \%$ chance of finding the differences between the means that were observed in this sample. Consequently, the null hypothesis of equal means is rejected. The significance of $\mathrm{F}$ is .000 which is less than the criterion value of .05 . Hence, there was a significant difference between the students' scores for the four units.

Table 5. Tests of Within-Subjects Effects

\begin{tabular}{|l|l|l|l|l|l|l|l|}
\hline \multicolumn{2}{|l|}{ Measure: MEASURE_1 } & $\begin{array}{l}\text { Type III Sum } \\
\text { of Squares }\end{array}$ & df & $\begin{array}{l}\text { Mean } \\
\text { Squrce }\end{array}$ \\
& Sphericity Assumed & 152.764 & 3 & F & Sig. & $\begin{array}{l}\text { Partial Eta } \\
\text { Squared }\end{array}$ \\
\cline { 2 - 9 } & Greenhouse-Geisser & 152.764 & 2.608 & 58.575 & 22.702 & .000 & .217 \\
\cline { 2 - 9 } & Huynh-Feldt & 152.764 & 2.697 & 56.642 & 22.702 & .000 & .217 \\
\cline { 2 - 9 } & Lower-bound & 152.764 & 1.040 & 146.888 & 22.702 & .000 & .217 \\
\hline \multirow{5}{*}{ Error(unit) } & Sphericity Assumed & 491.213 & 219 & 2.243 & & & \\
\cline { 2 - 9 } & Greenhouse-Geisser & 491.213 & 129.275 & 3.799 & & & \\
\cline { 2 - 9 } & Huynh-Feldt & 491.213 & 143.192 & 3.430 & & & \\
\cline { 2 - 9 } & Lower-bound & 491.213 & 52.986 & 9.271 & & & \\
\hline
\end{tabular}

The pairwise comparisons are presented in Table 6 that show whether the difference between each pair of units is significant. The only significant differences between group means were between units 1 and 3 , units 1 and 4, units 2 and 3, and units 2 and 4 . No other differences were significant. 
Table 6. Pairwise Comparisons

\begin{tabular}{|c|c|c|c|c|c|c|}
\hline \multirow[t]{2}{*}{ (I) unit } & \multirow[t]{2}{*}{ (J) unit } & \multirow{2}{*}{$\begin{array}{l}\text { Mean } \\
\text { Difference } \\
(\mathrm{I}-\mathrm{J}) \\
\end{array}$} & \multirow[t]{2}{*}{ Std. Error } & \multirow[t]{2}{*}{ Sig. ${ }^{\mathrm{b}}$} & \multicolumn{2}{|c|}{$\begin{array}{l}95 \% \text { Confidence Interval for } \\
\text { Difference }^{\mathrm{b}}\end{array}$} \\
\hline & & & & & Lower Bound & Upper Bound \\
\hline \multirow{3}{*}{1} & 2 & -.623 & .298 & .258 & -1.412 & .190 \\
\hline & 3 & $-1.785^{*}$ & .315 & .000 & -2.589 & -.938 \\
\hline & 4 & $-2.104^{*}$ & .402 & .000 & -3.162 & -.945 \\
\hline \multirow{3}{*}{2} & 1 & .623 & .298 & .258 & -.190 & 1.412 \\
\hline & 3 & $-1.176^{*}$ & .287 & .002 & -1.948 & -.419 \\
\hline & 4 & $-1.523^{*}$ & .358 & .001 & -2.396 & -.426 \\
\hline \multirow{3}{*}{3} & 1 & $1.785^{*}$ & .315 & .000 & .938 & 2.589 \\
\hline & 2 & $1.176^{*}$ & .287 & .002 & .419 & 1.948 \\
\hline & 4 & -.247 & .354 & 1.000 & -1.176 & .703 \\
\hline \multirow{3}{*}{4 (posttest) } & 1 & $2.104^{*}$ & .402 & .000 & .945 & 3.162 \\
\hline & 2 & $1.523^{*}$ & .358 & .001 & .426 & 2.396 \\
\hline & 3 & .247 & .354 & 1.000 & -.703 & 1.176 \\
\hline \multicolumn{7}{|c|}{ Based on estimated marginal means } \\
\hline \multicolumn{7}{|c|}{ *. The mean difference is significant at the .05 level. } \\
\hline
\end{tabular}

The mean science achievement score was 86.49 on unit $1 ; 87.13$ on unit $2,88.17$ on unit 3 , and 88.46 on unit 4. ANOVA shows that students' scores on the four units are significantly different, $F(3,219)=22.702$, $\mathrm{p}<0.0005$. The null hypothesis that the means of the scores on the four unit tests are the same is rejected, so at least one unit has a different mean. There is strong evidence to support the assertion that there is a difference in the mean scores of the four units. It seems that the use of interactive multimedia technology in instruction causes an initial improvement in students' achievement in science.

\section{CONCLUSIONS}

Interactive multimedia technology has the potential to improve student learning, achievement and motivation (Butts, 2008; Cottrell, 2014). The use of multimedia in instruction allows the combination of educational material that can provide more than one learning modality (Morano, 2014). Including more than one learning modality can be more effective in meeting students' various learning needs (Malik, 2010). Results from one-way repeated measures ANOVA revealed that there was a change in students' scores across the four units. There was a statistically significant effect for the science units $F(3,219)=22.702, p<0.0005$. Students had a higher score on the posttest for unit 4 that was taught using interactive multimedia technology in instruction while they obtained lower mean scores on the tests for units 1,2 and 3 that were taught using traditional methods of instruction. It is assumed that the difference in mean scores is the result of the use of interactive multimedia in instruction. The current study attempted to present an instructional method that was based on the use of multimedia technology that can be used as an advancing learning tool in order to help students promote and develop problem-solving and higher order thinking skills, while being engaged in active, experiential and constructivist learning. The results of the study depict the need for a change in student expectations as the methods of instruction develop into more active and constructivist (Butts, 2008). The results of the current study illustrate that the use of multimedia technology in science instruction can provide benefits to the students and help them increase their achievement. In accordance with the theory of 
multimodal learning, the results of the study showed that students' achievement in science could be improved with the use of interactive multimedia technology in instruction. This finding extends results from previous studies that showed that the use of multimedia technology improved student learning and achievement (Adegoke, 2011; Dalal, 2014; So \& Kong, 2007). Multimedia offers students access to images, animations, sound, and video and creates a multi-modal learning environment that allows teachers to address students' needs individually, which is necessary in education (Malik, 2010).

The current study tried to make a contribution to research on the use of interactive multimedia technology in elementary education. Additional research is still needed on this research area. Generalization of the results of this study was limited. It is therefore suggested that future research should include a population with different conditions with regards to sample size, student age, geography and subject matter. Multimedia present educational material in a multi-modal format and move the focus of instruction from instructors to the students (Chapman, 2013; Morano, 2014). The individualized nature of multimedia can challenge more students and increase their motivation in the classroom (Rhodes, 2013). The use of multimedia technology in a constructivist learning environment is more likely to result in continuous improvements in student learning, achievement and motivation (Dalal, 2014; Ramos \& De La Paz, 2010).

\section{REFERENCES}

Adegoke, B.A. (2011). Effect of multimedia instruction on senior secondary school students' achievement in physics. European journal of Educational Studies, 3(3), 537-550.

Birgan, L.J. (2010). The effects of multimedia technology on students' perceptions and retention rates in mathematics at a community college (Ed.D., Northcentral University)., 109. In ProQuest Dissertations and Theses, (275867748).

Butts, L.J. (2008). Exploring constructivist learning environments: a case study (Ed.D., University of Houston). In ProQuest Dissertations and Theses, (304604619).

Chapman, D.L. (2013). Multimedia instructional tools and student learning in computer application courses. (Ph.D., The University of Southern Mississippi)., 154. ProQuest Dissertations and Theses. (1461743173).

Cottrell,T.L. (2014). An assessment of the effect of multimedia on critical thinking outcomes. (Northern Illinois University). , 202. In ProQuest Dissertations and Theses, (1554012341).

Dalal, M. (2014). Impact of multi-media tutorials in a computer science laboratory course-an empirical study. The Electronic Journal of e-Learning, 12(4), 366-374.

Delgado, A. (2007). The effects of multimedia technology on the learning of math story problems of elementary and middle school deaf students. (M.S., Lamar University - Beaumont). 57. In ProQuest Dissertations and Theses, (1452086)

Du, X. (2013). An empirical study on multimedia-based social constructivist model in english vocabulary acquisition. Journal of Language Teaching and Research, 4(5), 1036-1043.

Garthwait, A. (2004). Use of hypermedia in one middle school: a qualitative field study. Journal of Educational Multimedia and Hypermedia, 13(3), 219-243.

Hunter, J. L., \& Krantz, S. (2010). Constructivism in cultural competence education. Journal of Nursing Education, 49(4), 207-14.

Johnson, T. (2009). The effect of closed interactive multimedia learning environments on student memory retention: A linear versus non-linear approach. (Ed.D., University of North Florida). , 120. In ProQuest Dissertations and Theses, (3354374).

Kingsley, K., \& Boone, R. (2008). Effects of multimedia software on achievement of middle school students in an american history class. Journal of Research on Technology in Education, 41(2), 203.

Malik, I.Z. (2010). Effects of multimedia-based instructional technology on African American ninth grade students' mastery of Algebra concepts. (Ed.D., University of Phoenix). In ProQuest Dissertations and Theses, (3452767).

Mazzotti, V.L. (2010). Effects of a multimedia goal-setting intervention on students' knowledge of the self-determined learning model of instruction and disruptive behavior. (Ph.D., The University of North Carolina at Charlotte). In ProQuest Dissertations and Theses, (3404854).

Morano, J.A. (2014). An exploration of multimedia reading instruction and its impact on students' online/offline reading comprehension. (Ph.D., Fordham University). , 219. In ProQuest Dissertations and Theses. (1561350869)

Neo, M., \& Neo, T.K. (2010). Students' perceptions in developing a multimedia project within a constructivist learning environment: a Malaysian experience. The Turkish Online Journal of Educational Technology, 9(1), 176-184. 
Papanastasiou, E.C., \& Zembylas, M. (2004). Differential effects of science attitudes and science achievement in Australia, Cyprus, and the USA. International Journal of Science Education, 26(3), 259-280.

Ramos, P.H., \& De La Paz, S. (2010). Learning history in middle school by designing multimedia in a project-based learning experience. Journal of Research on Technology in Education, 42(2), 151-173.

Rhodes, A.E. (2013). The effect of teacher designed multimedia on student comprehension and retention rates within introductory college science courses. (Ph.D., Kansas State University)., 178. In ProQuest Dissertations and Theses. (1417767259).

Singleton, C.M. (2009). An examination of student attitudes and understanding of exponential functions using interactive instructional multimedia. (Ph.D., Southern University and Agricultural and Mechanical College)., 88. In ProQuest Dissertations and Theses, (3465446).

So, W.W., \& Kong, S. (2007). Approaches of inquiry learning with multimedia resources in primary classrooms. Journal of Computers in Mathematics and Science Teaching, 26(4), 329-354.

Stokes, S.D. (2011). A multi-metric assessment on the impact of I Can LearnRTM (ICL) multimedia on actual and perceived student achievement in developmental mathematics. (Ph.D., Southern University and Agricultural and Mechanical College)., 91. In ProQuest Dissertations and Theses, (3454223).

Trochim, W., \& Donnelly, J. (2008). The research methods knowledge base (3rd ed.). Mason, OH: Cengage Learning.

Ulusoy, K. (2011). Effects of multimedia usage in students' attitude towards Turkish Republic Revolution History and Kemalism Lesson. Educational Research and Reviews, 6(4), 358-366.

Weiss, I., Kramarski, B., \& Talis, S. (2006). Effects of multimedia environments on kindergarten children's mathematical achievements and style of learning. Educational Media International, 43(1), 3-17.

Yamauchi, L. (2008). Effects of multimedia instructional material on students' learning and their perceptions of the instruction. (M.S., Iowa State University). , 61. In ProQuest Dissertations and Theses, (1453140).

Zheng, R. Z., Yangt, W., Garcia, D., \& McCadden, E. P. (2008). Effects of multimedia and schema induced analogical reasoning on science learning. Journal of Computer Assisted Learning, 24(6), 474-482. 